\title{
IPTEKS UPAYA PENINGKATAN HASIL PENERIMAAN PAJAK BERDASARKAN EFEKTIVITAS PELAKSANAAN PEMERIKSAAN PAJAK PADA KANTOR PELAYANAN PAJAK PRATAMA MANADO
}

\author{
Grefis Karaseran $^{1}$, Fanda Rundengan ${ }^{2}$ \\ ${ }^{1,2}$ Jurusan Akuntansi, Fakultas Ekonomi dan Bisnis, Universitas Sam Ratulangi, Kampus Unsrat, Sulawesi \\ Utara, 95115, Indonesia \\ E-mail : grefiskaraseran@gmail.com
}

\begin{abstract}
In the economy in Indonesia alone taxes have a very vital role. Indonesia itself adheres to the self assessment system, this opens a gap for taxpayers to act dishonestly. Therefore the Directorate General of Taxes is obliged to carry out administrative supervision as well as through tax audits. The purpose of the tax audit is to test compliance with the obligations of taxpayers. The research method used was descriptive research based on SP2 and SKP data from Manado Primary Tax Office. Based on three years, namely from 2014, 2015, and 2016 the percentage level of SP2 examination effectiveness is always on a very effective criterion, but in the next two years, from 2017 and 2018, the percentage level of SP2 examination effectiveness has decreased which is in the less effective criteria. Based on SKP data for the past 5 years, the level of acceptance has not been effective because it has reached the set target.
\end{abstract}

Keywords : Effectiveness, Tax Audit, Tax Revenue

\section{PENDAHULUAN}

Pajak merupakan tagihan wajib dari rakyat untuk negara yang berdasarkan undangundang (bersifat memaksa) dan tidak mendapat jasa timbal (kontraprestrasi) yang lansung dapat ditunjukkan dan digunakan untuk pengeluaran yang bermanfaat bagi masyarakat. Dalam perekonomian di Indonesia sendiri pajak memiliki peranan yang sangat vital. Menurut data Badan Pusat Statistik (BPS) dari tahun 2011-2014, pajak merupakan sumber utama penerimaan negara yaitu menyumbang sekitar $70 \%$ dari seluruh penerimaan negara. Indonesia sendiri menganut sistem self assessment system. Menurut Undang-Undang KUP, Self Assessment System adalah suatu sistem perpajakan yang diterapkan di Indonesia dengan memberikan tanggung jawab dan wewenang kepada Wajib Pajak untuk berinisiatif mendaftarkan diri untuk mendapat Nomor Pokok Wajib Pajak (NPWP), serta menghitung, menyetor, dan melaporkan sendiri jumlah pajak terhutang setiap tahun sesuai dengan UU perpajakan yang berlaku. Selain itu Self assessment system yang diterapkan ini dapat membuat para Wajib Pajak berlaku curang yaitu dengan cara melapor jumlah pajak yang terutang tidak sesuai dengan fakta. Maka dari itu Direktorat Jenderal Pajak bertanggung jawab untuk melaksanakan pengawasan serta memberikan para Wajib Pajak pembinaan kepatuhan baik dengan cara pengawasan administrasi ataupun dengan cara pemeriksaan pajak.

Menurut Mardiasmo (2011) Pemeriksaan pajak merupakan rangkaian aktivitas memeriksa, menghimpun, serta mengelolah data atau informasi lain untuk menilai tingkat kepatuhan kewajiban perpajakan serta untuk tujuan lain dalam melaksanaan ketentuan dalam UU perpajakan. Pemeriksaan pajak bertujuan adalah untuk menguji tingkat kepatuhan Wajib Pajak dalam memenuhi kewajiban sebagai bentuk untuk memberikan kepastian hukum, keadilan serta pembinaan, juga untuk maksud yang lain sebagai bentuk pelaksanakan ketentuan peraturan perundang-undangan perpajakan. Dengan adanya pemeriksaan pajak, 
Fiskus dapat mengetahui tingkat kepatuhan dari Wajib Pajak dalam rangka memaksimalkan penerimaan pajak. Sebagai bentuk pengawasan dan pembinaan kepada WP dalam melaksanakan pemungutan pajak, fiskus akan melaksanakan pemeriksaan pajak secara berkelanjutan dari tahun ke tahun.

Berdasarkan latar belakang ini, maka ipteks ini bertujuan untuk menentukan tingkat efektivitas dari Kantor Pajak Pratama (KPP) Pratama Manado dengan cara mengukur tingkat efektivitas pelaksanaan pemeriksaan pada Kantor Pelayanan Pajak (KPP) Pratama Manado. Tingkat presentase efekvitas pemeriksaan pajak sendiri dapat diukur dari data penyelesaian Surat Perintah Pemeriksaan (SP2) di tiap tahun serta bersumber pada penerimaan pemeriksaan pajak yang terealisasi berdasarkan SKP. Dari latar belakang yang telah dijelaskan, judul penelitian ini adalah Upaya Peningkatkan Hasil Penerimaan Pajak Berdasarkan Efektivitas Pelaksanaan Pemeriksaan Pajak Pada Kantor Pelayanan Pajak Pratama Manado.

\section{TINJAUAN PUSTAKA}

Akuntansi Pajak. Akuntansi Pajak menurut Agoes dan Estralita (2013:10) merupakan proses menentukan besaran pajak yang terutang bersumber pada laporan keuangan perusahaan yang telah dibuat.

Fungsi Pajak. Pajak menurut Rahayu (2013:26) mempunyai dua fungsi, yakni fungsi regulerend dan fungsi budgetair. Fungsi pajak sebagai regulerend, yaitu pajak digunakan sebagai pengontrol ekonomi dari suatu negara. Pajak berfungsi sebagai budgetair, yaitu pajak memiliki fungsi sebagai sumber pokok dari penerimaan suatu bangsa yang berguna buat pembiayaan kepentingan suatu bangsa. Dari kedua fungsi pajak ini tercermin pentingnya pengaruh pajak untuk suatu bangsa.

Pemeriksaan Pajak. Menurut Waluyo dan Wirawan B.Ilyas (2001 : 10) Pemeriksaan pajak adalah rangkaian aktivitas untuk mencari, mengumpulkan, serta mengolah data dan keterangan yang lain, dalam rangka untuk menguji kepatuhan kewajiban pemenuhan perpajakan serta untuk tujuan yang lain, dalam hal untuk melaksanakan ketentuan dari peraturan perundang-undangan perpajakan.

Penerimaan Pajak. Menurut John Hutagaol (2007:325) Penerimaan pajak adalah penghasilan yang bersumber dari penerimaan pajak masyarakat yang diperoleh secara berkesinambungan dan kemudian digunakan secara optimal oleh pemerintah sesuai keadaan dan kebutuhan masyarakat.

Efektivitas. Pengertian efektivitas menurut Mardiasmo (2002:132) merupakan kaitan dari antara tujuan yang ingin diraih dengan hasil yang telah dilaksanakan. Suatu kegiatan dapat dibilang efektif jika kegiatan tersebut meraih target atau melampaui target yang telah dibuat. Rumus yang digunakan untuk mengukur tingkat efektivitas pelaksanaan pemeriksaan pajak adalah sebagai berikut:

Rumus untuk Surat Perintah Pemeriksaan (SP2) :

$$
\text { Efektivitas }=\frac{\text { Jumlah Penyelesaian }}{\text { Target Penyelesaian }+\mathrm{n}} \times 100 \%
$$

Ket: $\mathrm{n}=$ Tunggakan pemeriksaan dari tahun sebelumnya kalau ada

Rumus untuk Pemeriksaan Surat Ketetapan Pajak :

$$
\text { Efektivitas }=\frac{\text { Realisasi Pemeriksaan }}{\text { Target Pemeriksaan }} \times 100 \%
$$


Setelah melakukan pengukuran tingkat efektivitas, kemudian hasil pengukuran dikelompokan berdasarkan tabel berikut:

Tabel 1. Persentase efektivitas dan kriterianya

\begin{tabular}{lc}
\hline \multicolumn{1}{c}{ Presentase Efektivitas } & Kriteria \\
\hline$>100 \%$ & Sangat efektif \\
$90 \%-100 \%$ & Efektif \\
$80 \%-90 \%$ & Cukup Efektif \\
$60 \%-80 \%$ & Kurang Efektif \\
$<60 \%$ & Tidak Efektif \\
\hline
\end{tabular}

Sumber : Kementerian Dalam Negeri, 2018

\section{METODE DAN TEKNIK PENERAPAN IPTEKS}

3.1. Metode Penerapan Ipteks

Penerapan metode ipteks yang digunakan yaitu penerimaan pajak dianalisis berdasarkan konsep efektivitas dalam rangka meningkatkan hasil penerimaan pajak.

\subsection{Teknik Penerapan Ipteks}

Penerapan teknik ipteks yaitu menerapkan perhitungan tingkat pencapaian dan indikator-indikator dalam konsep efektivitas berdasarkan data pemeriksaan.

\section{PEMBAHASAN}

\subsection{Gambaran Objek Penerapan Ipteks}

Kantor Pelayanan Pajak (KPP) Pratama Manado merupakan salah satu kantor di area Manado yang melayani administrasi pajak, yang berada di bawah naungan Direktorat Jendral Pajak merupakan Badan Usaha Milik Negara (BUMN) di bawah Kementrian Keuangan. Beralamat di Jalan Gunung Klabat, Tanjung Batu, Wanea, Kota Manado, yang pada November tahun 2008 peresmiannya dilakukan oleh Menteri Keuangan Republik Indonesia, Sri Mulyani Indrawati, dan mulai beroperasi pada 1 Desember 2008 dengan tugas melaksanakan penyuluhan, pelayanan, dan pengawasan kepada Wajib Pajak.

\subsection{Pembahasan}

1. Efektivitas Pelaksanaan Penerimaan Pajak berdasarkan Surat Perintah Pemeriksaan dan berdasarkan Surat Ketetapan Pajak (SKP)

Tabel 2. Target pemeriksaan dan realisasi pemeriksaan

\begin{tabular}{cccc}
\hline Tahun & Target Pemeriksaan & $\begin{array}{c}\text { Realisasi } \\
\text { Pemeriksaan }\end{array}$ & Tunggakan \\
\hline 2014 & 126 & 138 & 0 \\
2015 & 114 & 167 & 0 \\
2016 & 165 & 170 & 0 \\
2017 & 441 & 333 & 108 \\
2018 & 418 & 286 & 132 \\
\hline
\end{tabular}

Sumber : KPP Pratama Manado, 2018

Berdasarkan data diatas, terdapat data target pemeriksaan dan realisasi surat perintah pemeriksaan dari tahun 2014-2018. Diketahui pada tahun 2014 realisasi pemeriksaan SP2 yang diperoleh KPP Pratama Manado adalah sebesar 138, dimana realisasi tersebut telah melampaui target yang telah ditentukan sebelumnya yaitu sebesar 126 SP2. Pada tahun 2015 jumlah realisasi pemeriksaan adalah sebesar 167 SP2, jauh melampaui dari target pemeriksaan yang ditetapkan yaitu sebesar 114 SP2. Pada tahun 2016 realisasi pemeriksaan SP2 yang diperoleh adalah sebesar 170 dan telah melebihi target yang telah 
ditentukan yaitu sebesar 165 SP2. Pada tahun 2017 realisasi pemeriksaan SP2 adalah sebesar 333, hal ini mengalami penurunan dari target yang ditentukan yaitu sebesar 441 SP2, sehingga menyisakan tunggakan 108 SP2. Pada tahun 2018 realisasi penerimaan pemeriksaan yaitu sebesar $286 \mathrm{SP} 2$, hal ini mengakibatkan tidak tercapainya target pemerikasaan yang telah ditetapkan yakni sebesar 418 SP2.

\section{Perhitungan Efektivitas}

Tahun 2014

Efektivitas $=\frac{138}{126} \times 100 \%=109,5 \%$

Tahun 2015

Efektivitas $=\frac{167}{114} \times 100 \%=146,4 \%$

Tahun 2016

Efektivitas $=\frac{170}{165} \times 100 \%=103 \%$

Tahun 2017

Efektivitas $=\frac{333}{441} \times 100 \%=75,5 \%$

Tahun 2018

Efektivitas $=\frac{286}{418+108} \times 100 \%=54,3 \%$

Tabel 3. Efektivitas dan kriteria

\begin{tabular}{cccccc}
\hline Tahun & $\begin{array}{c}\text { Target } \\
\text { Pemeriksaan }\end{array}$ & $\begin{array}{c}\text { Realisasi } \\
\text { Pemeriksaan }\end{array}$ & Tunggakan & $\begin{array}{c}\text { Presentase } \\
\text { Efektivitas }\end{array}$ & Kriteria \\
\hline 2014 & 126 & 138 & 0 & $109,5 \%$ & Sangat efektif \\
2015 & 114 & 167 & 0 & $146,4 \%$ & Sangat efektif \\
2016 & 165 & 170 & 0 & $103 \%$ & Sangat Efektif \\
2017 & 441 & 333 & 108 & $75,5 \%$ & Kurang efektif \\
2018 & 418 & 286 & 132 & $68,4 \%$ & Kurang efektif \\
\hline
\end{tabular}

Sumber : KPP Pratama Manado, 2018

Berdasarkan pada perhitungan efektivitas dan data tabel diatas, diketahui pada tahun 2014, tingkat efektivitas yang dicapai yaitu sebesar 109,5\%, maka kriteria yang diraih berada pada tingkat sangat efektif. Tahun 2015 tingkat kriteria yang diraih yaitu sangat efektif, hal ini disebabkan karena tingkat presentase efektivitas yang mencapai 146,4\%. Pada tahun 2016, dicapai angka presentase sebesar 103\%, maka kriteria efektivitas yang dicapai termasuk berada pada tingkat sangat efektif. Pada tahun 2017, tingkat efektivitas termasuk pada kriteria kurang efektif, hal ini disebabkan tidak tercapainya antara realisasi pemeriksaan yang hanya sebesar 333 SP2 dan target pemeriksaan yakni sebesar 441 SP2, sehingga menyisakan 
tunggakan sebesar 108 SP2. Pada tahun 2018, tingkat efektivitas masih termasuk pada kriteria kurang efektif, hal ini disebabkan karena tidak tercapainya angka realisasi pemeriksaan yang hanya sebesar 286 SP2 dengan target pemeriksaan yakni sebesar 418 SP2 ditambah juga tunggakan SP2 tahun sebelumnya yaitu sebesar 108 SP2. Berdasarkan dari uraian diatas, selama tiga tahun yaitu dari tahun 2014, 2015, dan 2016 tingkat presentase efektivitas pemeriksaan SP2 selalu berada pada kriteria sangat efektif, hal ini penyebabnya karena tingkat realisasi pemeriksaan selalu melewati dari target yang telah dibuat dengan presentase efektivitas di atas $100 \%$, akan tetapi dua tahun berikutnya yaitu dari tahun 2017 dan 2018, tingkat presentase efektivitas pemeriksaan SP2 mengalami penurunan yaitu berada pada kriteria kurang efektif, hal ini disebabkan karena realisasi pemeriksaan tidak mencapai target yang ditetapkan yaitu berada pada angka $60-80 \%$.

\section{Analisis Efefktivitas berdasarkan pada Pemeriksaan SKP}

Tabel 4. Target dan realisasi penerimaan

\begin{tabular}{crr}
\hline Tahun & Target Penerimaan & Realisasi Penerimaan \\
\hline 2014 & 18.913 .636 .000 & 10.357 .995 .939 \\
2015 & 44.267 .000 .000 & 27.856 .790 .493 \\
2016 & 72.570 .030 .000 & 15.393 .992 .033 \\
2017 & 97.654 .456 .000 & 6.394 .819 .260 \\
2018 & 54.906 .070 .000 & 10.641 .257 .799 \\
\hline
\end{tabular}

Sumber : KPP Pratama Manado, 2018

Berdasarkan data diatas menunjukkan bahwa dimana dalam kurun waktu 5 tahun terakhir dari tahun 2014 sampai 2018 KPP Pratama Manado belum dapat meningkatkan realisasi pemeriksaan dari target yang telah ditentukan.

\section{Perhitungan Efektivitas}

Tahun 2014

Efektivitas $=\frac{10.357 .995 .939}{18.913 .636 .000} \times 100 \%=54,7 \%$

Tahun 2015

Efektivitas $=\frac{27.856 .790 .493}{44.267 .000 .000} \times 100 \%=62,9 \%$

Tahun 2016

Efektivitas $=\frac{15.393 .992 .033}{72.570 .030 .000} \times 100 \%=21,2 \%$

Tahun 2017

Efektivitas $=\frac{6.394 .819 .260}{97.654 .456 .000} \times 100 \%=6,5 \%$

Tahun 2018

Efektivitas $=\frac{10.641 .257 .799}{54.906 .070 .000} \times 100 \%=19,3 \%$ 
Tabel 5. Efektivitas dan kriteria

\begin{tabular}{ccccc}
\hline Tahun & $\begin{array}{c}\text { Target } \\
\text { Penerimaan }\end{array}$ & $\begin{array}{c}\text { Realisasi } \\
\text { Penerimaan }\end{array}$ & $\begin{array}{c}\text { Presentase } \\
\text { Efektivitas }\end{array}$ & Kriteria \\
\hline 2014 & 18.913 .636 .000 & 10.357 .995 .939 & $54,7 \%$ & Tidak Efektif \\
2015 & 44.267 .000 .000 & 27.856 .790 .493 & $62,9 \%$ & Kurang Efektif \\
2016 & 72.570 .030 .000 & 15.393 .992 .033 & $21,2 \%$ & Tidak Efektif \\
2017 & 97.654 .456 .000 & 6.394 .819 .260 & $6,5 \%$ & Tidak Efektif \\
2018 & 54.906 .070 .000 & 10.641 .257 .799 & $19,3 \%$ & Tidak Efektif \\
\hline
\end{tabular}

Sumber : KPP Pratama Manado, 2018

Berdasarkan pada perhitungan efektivitas dan data tabel diatas. Diketahui pada tahun 2014 tingkat presentse efektivitas yang dicapai adalah sebesar 54,7\% hal ini tergolong dalam tingkat kriteria yang tidak efektif. Hal ini disebabkan karena realisasi penerimaan pemeriksaan yang diperoleh adalah sebesar Rp. 10.357.995.939 dari target penerimaan yang ditetapkan sebelumnya sebesar Rp. 18.913.636.000. Pada tahun 2015 tingkat presentse efektivitas yang dicapai adalah sebesar 62,9\% hal ini termasuk dalam kriteria kurang efektif. Penyebabnya karena perolehan penerimaan pemeriksaan yang terealisasi adalah sebesar Rp. 15.393.992.033 dari target penerimaan yang ditetapkan sebelumnya sebesar Rp. 44.267.000.000. Pada tahun 2016 tingkat presentse efektivitas yang dicapai adalah sebesar $21,2 \%$ hal ini tergolong dalam kriteria yang tidak efektif. Hal ini disebabkan karena perolehan penerimaan pemeriksaan yang terealisasi adalah sebesar Rp. 10.357.995.939 dari target penerimaan yang ditetapkan sebelumnya sebesar Rp. 72.570.030.000.

Pada tahun 2017 tingkat presentse efektivitas yang dicapai adalah sebesar 6,5\% hal ini tergolong kriteria yang tidak efektif. Hal ini disebabkan karena perolehan penerimaan pemeriksaan yang direalisasi adalah sebesar Rp. 6.394.819.260 dari target penerimaan yang ditetapkan sebelumnya sebesar Rp. 97.654.456.000. Pada tahun 2018 tingkat presentse efektivitas yang dicapai adalah sebesar 19,3\% hal ini termasuk dalam kriteria tidak efektif. Hal ini disebabkan karena perolehan penerimaan pemeriksaan yang direalisasikan adalah sebesar Rp. 10.641.257.799 dari target penerimaan yang ditetapkan sebelumnya sebesar Rp. 54.906.070.000. Berdasarkan uraian data diatas, diketahui pada tahun 2014 ke 2015 presentase efektivitas mengalami peningkatan, akan tetapi dari tahun 2015 ke 2016 presentase efektivitas mengalami penurunan, hal ini berlanjut pada tahun berikutnya yaitu pada tahun 2016 ke 2017 presentase efektivitas mengalami penurunan, selanjutnya dari tahun 2017 ke 2018 presentase efektivitas kembali mengalami peningkatan.

\section{KESIMPULAN DAN SARAN}

\subsection{Kesimpulan}

Penerimaan pajak adalah penghasilan yang bersumber dari penerimaan pajak masyarakat yang diperoleh secara berkesinambungan dan kemudian digunakan secara optimal oleh pemerintah sesuai keadaan dan kebutuhan masyarakat. Salah satu upaya untuk meningkatkan hasil penerimaan pajak pada Kantor Pelayanan Pajak (KPP) Pratama Manado adalah dengan menganalisis efektivitas pelaksanaan pemeriksaan. Berdasarkan dari hasil pembahasan di atas, tingkat efektivitas berdasarkan Surat Perintah Pemeriksaan (SP2), dapat disimpulkan efektif, hal ini bisa dilihat dari data tahun 2014, 2015, dan 2016 tingkat presentase efektivitas di atas $100 \%$, meskipun pada dua tahun selanjutnya yaitu tahun 2017 dan 2018 mengalami penurunan tetapi masih berada pada presentase angka 60-80\%. Kemudian pada efektivitas pelaksanaan penerimaan berdasarkan Surat Ketetapan Pajak 
(SKP), dapat disimpulkan belum efektif, hal ini karena berdasarkan data lima tahun terakhir, KPP Pratama Manado belum bisa merealisasikan target penerimaan yang telah ditetapkan.

\subsection{Saran}

Berdasarkan pembahasan dan kesimpulan yang ada, KPP Pratama Manado harus melakukan peningkatan kualitas maupun peningkatan jumlah pegawai pemeriksaan agar bisa meningkatkan kinerja sehingga target-target yang ditetapkan bisa tercapai, selanjutnya juga KPP Pratama Manado harus melakukan penyuluhan-penyuluhan kepada masyarakat agar tingkat kesadaran masyarakat mengenai perpajakan semakin meningkat.

\section{DAFTAR PUSTAKA}

Undang-Undang Republik Indonesia Nomor 28 Tahun 2007 tantang Ketentuan Umum dan Tata Cara Perpajakan

Abdul Halim. 2004. Akuntansi Keuangan Daerah. Salemba Empat. Jakarta.

Agoes, Sukrisno., dan Estralita. (2013). Akuntansi Perpajakan Edisi 3. Salemba Empat. Jakarta.

Devi Septya Anggraini., Mochammad Al Musadieq., Dwiatmanto. 2016. Efektivitas Pelaksanaan Pemeriksaan Pajak Dalam Rangka Menigkatkan Penerimaan Pajak (Studi Pada Kantor Pelayanan Pajak Pratama Malang Selatan). Jurnal Perpajakan (JEJAK), Vol. 8, No. 1 (2016). 1-9.

Devid Giroth., David P.E. Saerang., Jessy D.L. Warongan. 2016. Efektivitas Pemeriksaan Pajak Dalam Upaya Menigkatkan Penerimaan Pajak Pada Kantor Pelayanan Pajak Pratama Manado. Jurnal Berkala Ilmiah Efefisiensi, Vol. 16, No. 4. 2016. 971-981.

Hutagaol, John. 2007. Perpajakan Isu - isu Kontemporer, Jakarta: Graha Ilmu.

Mardiasmo. 2002. Perpajakan Edisi Revisi 2002. ANDI. Yogyakarta.

Mardiasmo. 2011. Perpajakan Edisi Revisi 2011. ANDI. Yogyakarta.

Muljono. 2011. Hukum Pajak. ANDI. Yogyakarta

Rahayu, Kurnia, Siti. 2013. Konsep dasar dan pedoman pemeriksaan akuntan publik. Graha Ilmu. Yogyakarta.

Waluyo. 2012. Akuntansi pajak. Edisi 4. Salemba Empat. Jakarta.

Waluyo., dan Wirawan B. Ilyas. 2002. Perpajakan Indonesia. Salemba Empat. Jakarta.

www.pajak.go.id 